\title{
CYTOGENETIC STUDY FOR REPRODUCTIVE DISORDERS IN BUFFALO COWS
}

\author{
M.F. Saad, A.M. Saeed, S.A. Darawish and S.A. Sweify \\ Department of Animal Biotechnology, Animal Production Research Institute, Dokki, Giza, Egypt \\ PO Box 12816,E-mail: mohamedsfahmy@yahoo.com
}

\section{SUMMARY}

Cytogenetic analysis is one of the important tools to detect the reproductive failures in farm animals. The association of chromosome aberrations with causes of reduced fertility in buffalo cows, e.g. inactive and cystic ovaries, and repeat breeder were studied. A total of 33 Egyptian buffalo cows ranged from 3-6 years old were divided into four groups. The $1^{\text {st }}$ group was normal animals $(n=11)$. The $2^{\text {nd }}$ group was those suffering from smooth inactive ovaries $(n=8)$, whereas, the $3^{\text {rd }}$ group was suffering from cystic ovaries $(n=5)$ and the $4^{\text {th }}$ group was suffering from repeat breeding $(n=9)$. Cytogenetic examination was studied for every animal in all groups. The results showed that, the females suffering from repeat breeding had the highest means of structural chromosomal aberrations, as centromeric attenuation $(0.132 \pm 0.011)$, deletion $(0.13 \pm 0.009)$ and breaks $(0.125 \pm 0.009)$. The total structural chromosomal aberration was $(52.1 \%)$. The type of structural chromosomal aberration as centromeric attenuation chromosome was recorded highest means aberration types for both animals suffering from repeat breeding $(0.132 \pm 0.011)$, cystic ovaries $(0.123 \pm 0.01)$ and inactive ovaries (0.11 \pm 0.008$)$. Meanwhile, total percentages of numerical chromosomal aberrations were recorded highest in repeat breeder, cystic ovaries, inactive ovaries and normal groups $(21.6 \%, 13.3 \%, 10.8 \%$ and $2.2 \%)$ respectively. These results emphasize the association between the major fertility problems in buffalo cows and the studied chromosomal aberrations, which indicate possible utilization of such aberration for early culling of animals with reproductive disorders.

\section{Keywords: Buffalo, cytogenetic, chromosomal aberration, ovary, repeat breeder, fertility disorders}

\section{INTRODUCTION}

Buffalo is considered one of the most important multipurpose farm animals. The infertility problems are widely spread among this species causing excess reduction in their production.

Maintaining high fertility rate and economic return is the main goal of animal farming enterprises. Ovarian inactivity, silent heat, endometritis and repeat breeding are the main reproductive disorders in buffaloes in Egypt (Ahmed et al., 2010). Inactive ovaries and anestrous in both cows and buffaloes are usually leads to prolonged calving intervals and the resultant is an extensive economic loss. The incidence of inactive ovaries was recorded by many authors at several countries as $7 \%$ in Egyptian buffaloes. Ovarian cyst (OC) is an important ovarian dysfunction and a major cause of reproductive failure in dairy cattle (Ahmed et al., 2002).

Repeat breeding is usually defined as sub-fertile animal which mated three times during the proper period and does not become pregnant and continually return to service in the absence of any obvious pathological disorder in genital tract and has normal estrous cycle. It is an important syndrome causing great economic losses and effects on breeding animals (Dochi et al., 2008; Parkinson, 2009 and ElKhadrawy et al., 2011). Diagnosis of reproductive disorders relies on the animal records, rectal palpation, ultrasonography, vaginal examination, uterine culture, uterine biopsy and uterine endometrial cytology (Sheldon et al., 2006). Cytogenetic study has several applications in animal improvement and one of these is to diagnose genetic abnormalities especially chromosomal aberrations that are usually associated with sub-fertility, infertility, embryonic losses, still births and lower body mass as well as functional and more seldom phenotypic disturbances (Ioana-Nicolae, 2007; Murali et al., 2009 and Patel et al., 2012). Chromosomes structure aberration causes direct effects on fertility and reproductive outcome in farm animals. It could account for $20 \%$ of total embryonic and fetal losses in early fertile age because it may carry balanced autosome abnormalities which reduce the fertility (Maria and King, 2004 and Patel et al., 2012).

The aim of this study is detecting the relationship between some reproductive disorders (inactive ovary, cystic ovaries and repeat breeder) and the presence of some specific numerical and/or structural chromosomal aberrations, which can be used in early culling of heifers that carry different types of chromosomal aberrations.

\section{MATERIALS AND METHODS}

\section{Animals:}

A total of 33 Egyptian buffalo cows located at Mehallet Musa station, Animal Production Research Institute (APRI), Egypt. The age of animals ranged 36 years. 
Cows were maintained on standard ration correlated with their requirements according to NRC (2013). The cows were proved to be free from any detectable external or internal parasites. They were divided into four groups according to screening and their records. Animal groups consisted of eleven females of sexually normal breeding as $1^{\text {st }}$ group (G1), eight females suffering from smooth inactive ovaries as $2^{\text {nd }}$ group $(\mathrm{G} 2)$, five females suffering from cystic ovaries as $3^{\text {rd }}$ group (G3) and nine females suffering from repeat breeding as $4^{\text {th }}$ group (G4).

\section{Chromosomal preparation and analysis:}

Under hygienic, $3 \mathrm{ml}$ blood sample was collected from the jugular vein of each animal into sterilized sodium heparinized vacutainer tube with special care in handling. Chromosomal preparations were performed according to Halnan (1977) using standard whole blood culture in tissue culture 199 medium (M4531) supplemented with antibiotics (Streptomycin and Pencillin) (S2522), 20\% fetal calf serum (F2442), 0.1\% Phytoheamagglutanin and $0.1 \%$ L-Glutamin (G7513) were added to stimulate mitotic activity of the lymphocyte cells and to facilitate the identification of chromosomes. The blood culture was incubated at $37^{\circ} \mathrm{C}$ for 72 hours. To increase the relative frequency of prometaphase chromosomes, Colchicin (C180) $2 \mu \mathrm{g} / \mathrm{ml}$ was added to the culture for $2 \mathrm{~h}$, prior to the harvesting. The cells were harvested by centrifugation at $1500 \mathrm{~g}$ for 7 minutes followed by hypotonic treatment with $0.56 \%$ potassium chloride, (P1302) for 20 minutes at $37^{\circ} \mathrm{C}$ and fixative in $3: 1$ ratio of methanol (M0789) and acetic acid glacial. Finally, cell suspension was dropped on slides and air dried. Slides were conventionally stained in $10 \%$ Giemsa stain (G9641) for screening under the Nikon compound microscope attached with photographic system. About 50 metaphase spreads were screened to detect the chromosomal aberrations as (deletion, break, gap, ring, centromeric attenuation, CA and centric fusion, $\mathrm{CF}$, in structural aberrations) and (polyploidy and aneuploidy in numerical chromosomal aberrations), Iannuzzi and De Berardino (2008).

\section{Statistical model and analysis:}

Results were statistically analysed using ANOVA test of SPSS $_{14}$ (2006). applying the following model: $\mathrm{Y}_{\mathrm{ij}}=\mathrm{U}+\mathrm{S}_{\mathrm{i}}+\mathrm{e}_{\mathrm{ij}}$

Where, $\mathrm{Y}_{\mathrm{ij}}$ is the reproductive phenotype (normal, cystic ovaries ....etc., $\mathrm{i}=1$ to 4 ), $\mathrm{U}$ is the overall mean, $S_{i}$ is chromosomal aberration types in both structural and numerical aberrations measured on animals (deletion, break, gap ......etc.) and $\mathrm{e}_{\mathrm{ij}}$ is the random error.

\section{RESULTS AND DISCUSSION}

In the present work, the percentage of chromosomal aberrations and its relationship with the fertility of buffalo cows was studied. The results showed that, females suffering from repeat breeding (G4) showed significant $(\mathrm{P}<0.05)$ chromosomal aberrations especially in the means of break $(0.125 \pm 0.009)$, deletion $(0.130 \pm 0.009) \quad$ and centromeric attenuation $(0.132 \pm 0.011)$ compared to the normal group (G1), Table (1). Chromosomal analysis of smooth inactive ovaries (G2) showed clearly highly structure aberration in the means of ring type of aberration $(0.043 \pm 0.009)$ and centric fusion (0.08 \pm 0.008$)$. Generally, buffalo cows with reproductive problems (smooth inactive ovaries, G2; cystic ovaries, G3 and repeat breeding, G4) had significantly $(\mathrm{P}<0.05)$ higher structural chromosomal abnormalities than those recorded for healthy normal buffalo cows (G1). These results indicate possible relationship between the observed reproductive disorders of buffalo cows and the proportion of structural chromosomal aberrations they carried.

Table 1. Frequency of structural and numerical chromosomal aberrations detected in different failures in Egyptian buffalo cows (mean \pm S.E)

\begin{tabular}{cccccc}
\hline \multicolumn{2}{c}{$\begin{array}{c}\text { Chromosomal aberration } \\
\text { types }\end{array}$} & \multicolumn{4}{c}{ Animal Cases and Numbers } \\
\cline { 2 - 6 } Structural & Deletion & $0.035 \pm 0.005^{\mathrm{d}}$ & $0.073 \pm 0.008^{\mathrm{a}}$ & $0.100 \pm 0.007^{\mathrm{c}}$ & $0.130 \pm 0.009^{\mathrm{b}}$ \\
& Break & $0.020 \pm 0.005^{\mathrm{d}}$ & $0.080 \pm 0.008^{\mathrm{a}}$ & $0.072 \pm 0.007^{\mathrm{c}}$ & $0.125 \pm 0.009^{\mathrm{b}}$ \\
& Gap & $0.013 \pm 0.005^{\mathrm{b}}$ & $0.053 \pm 0.005^{\mathrm{a}}$ & $0.064 \pm 0.004^{\mathrm{a}}$ & $0.069 \pm 0.004^{\mathrm{a}}$ \\
& Ring & $0.002 \pm 0.002^{\mathrm{b}}$ & $0.043 \pm 0.009^{\mathrm{a}}$ & $0.008 \pm 0.005^{\mathrm{b}}$ & $0.035 \pm 0.005^{\mathrm{a}}$ \\
& C. A & $0.009 \pm 0.003^{\mathrm{b}}$ & $0.110 \pm 0.008^{\mathrm{a}}$ & $0.123 \pm 0.010^{\mathrm{a}}$ & $0.132 \pm 0.011^{\mathrm{a}}$ \\
\multirow{4}{*}{ Numerical } & C. F & $0.011 \pm 0.003^{\mathrm{ab}}$ & $0.080 \pm 0.008^{\mathrm{a}}$ & $0.030 \pm 0.014^{\mathrm{b}}$ & $0.030 \pm 0.006^{\mathrm{b}}$ \\
& Polyploidy & $0.009 \pm 0.003^{\mathrm{c}}$ & $0.500 \pm 0.005^{\mathrm{a}}$ & $0.048 \pm 0.008^{\mathrm{a}}$ & $0.096 \pm 0.011^{\mathrm{b}}$ \\
& Aneupuloidy & $0.013 \pm 0.004^{\mathrm{d}}$ & $0.058 \pm 0.010^{\mathrm{a}}$ & $0.085 \pm 0.007^{\mathrm{c}}$ & $0.120 \pm 0.007^{\mathrm{b}}$ \\
\hline
\end{tabular}

a,b,c,d and values with different letters in same raw are significantly different $(\mathrm{P}<0.05)$.

C.A (Centromeric Attenuation) and C.F (Centric Fusion). Each 50 cells were examined per animal.

Also, the total structural chromosomal abnormalities percentages (Fig. 1) in the different groups were $52.1 \%, 43.9 \%, 39.7 \%$ and $9 \%$ in $\mathrm{G} 4$, G2, G3 and G1, respectively. Break usually occurs in one of the chromatid, transfer part of chromatid to the other one or break in all chromosomes. It is usually associated with missing of genes carried in the second generation. It explains the reduction in fertility and the loss of production (El-Bayomi et al., 2011; Patel et al., 2012 and Genualdo et al., 2012). 
Numerical chromosomal analysis clearly showed that repeat breeding group (G4) had high significantly $(\mathrm{P}<0.05)$ in presence of polyploidy chromosomes $(0.096 \pm 0.011)$ and aneuploidy chromosomes $(0.12 \pm 0.007)$ compared with normal group (G1), (Table 1). The total numerical aberration chromosomes station percentages, Fig. (1) were 21.6
$\%, 13.3 \%$ and $10.8 \%$ in repeat breeding (G4), cystic ovaries (G3), smooth in active ovary (G2) respectively, compared to normal females $2.2 \%(\mathrm{G} 1)$. Some images of structural chromosomal abnormalities e.g. deletion, break and centromeric attenuations were showed in Fig. (2).

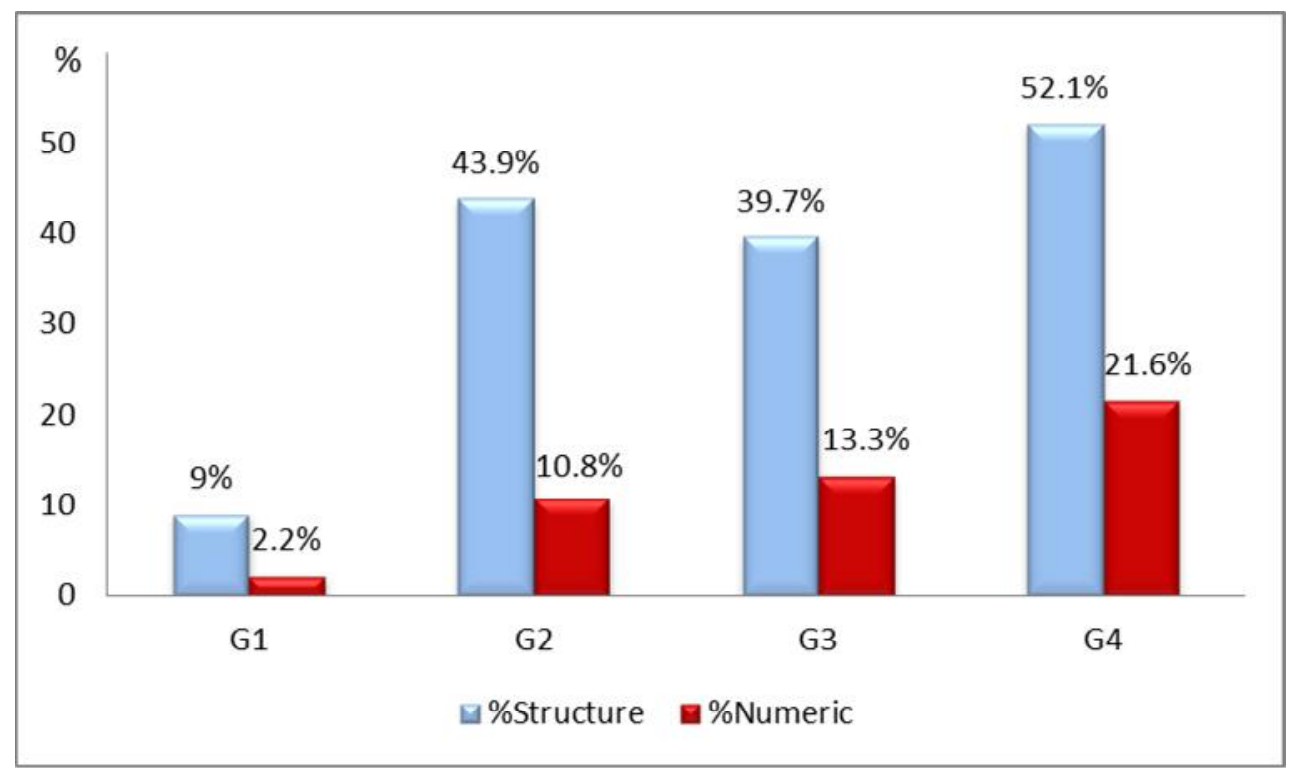

Fig. 1. Total percentage of structural and numerical chromosomal aberrations in reproductive failures in Egyptian buffalo cows.

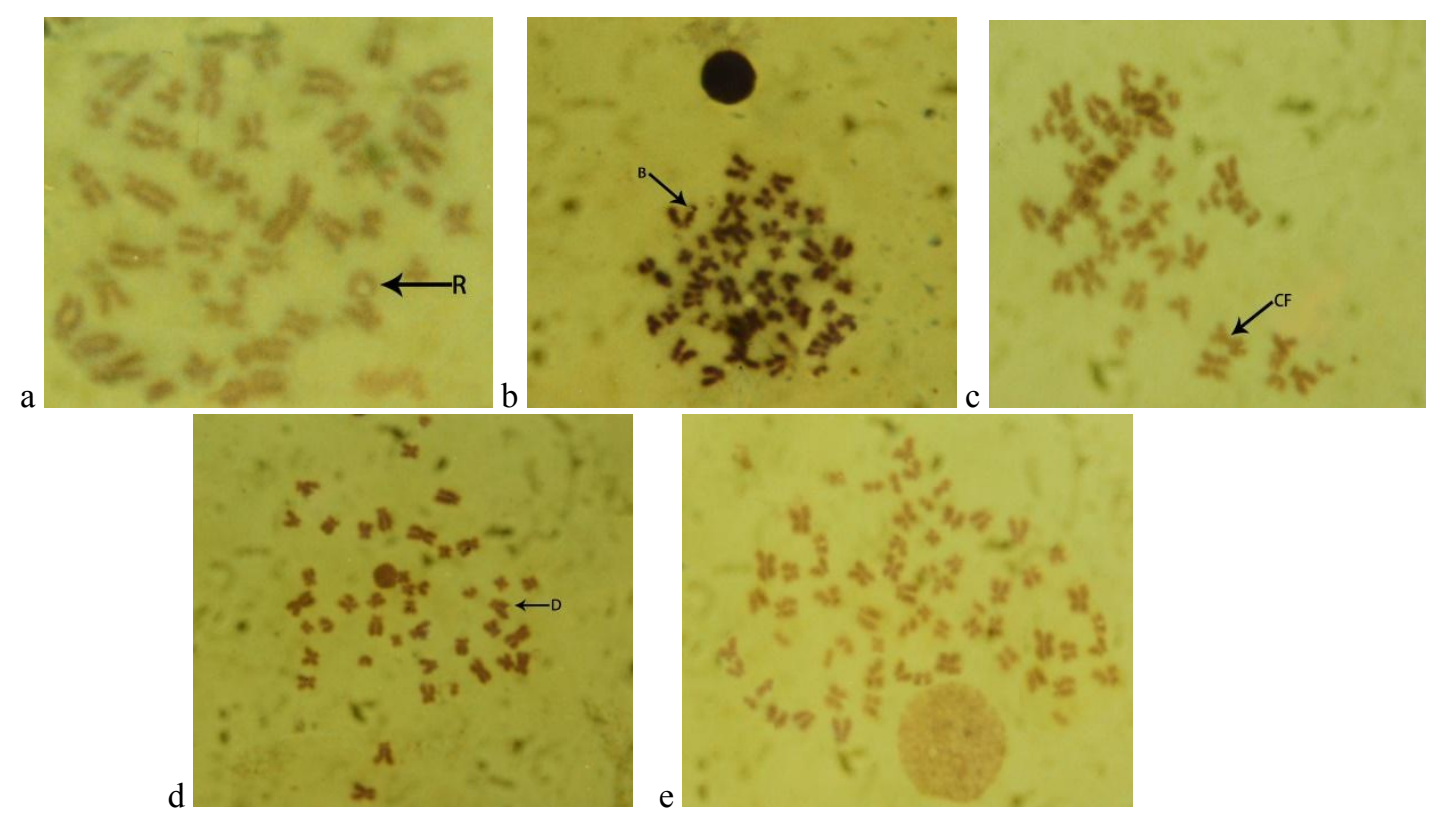

Fig. 2. Metaphase spread showing structural and Numerical aberration as (a) ring, (b) break, (c) centric fusion, (d) deletion and (e) polyploidy types of Egyptian buffalo cows

Polyploidy in male and female animals participate in sexual cycle and many genetic diseases and sterility or parthenogenesis. Aneuploidy set differs from wild type by only one chromosome or by a small number of chromosomes. The aneuploidy condition $2 \mathrm{n}-1$ is called monosomic (means 'one chromosome') because there is only one copy of some specific chromosome present instead of the usual two found in its diploid progenitor (Patel et al., 2006 and Di Meo et al., 2008 and 2011). 
The numerical and structural chromosome abnormalities associated with unbalanced chromosome segregation at meiotic anaphase I or anaphase II, may occur in gametogenesis meiosis division and cases sterility animals or lowered fertility. In addition, autosomal aneuploidy during mitoses division in prenatal development could be cases increasing embryonic mortality rate (Maria and king 2004; Saleh et al., 2008 and El-Bayomi et al., 2011). The present study showed positive correlation between chromosomal abnormalities (structural and numerical) and reproductive failures or fertility problems. Also, low means of chromosomal aberrations in different types of abnormalities were inconsistent for particular sample; therefore, their effects may not be obvious on fertility in the normal females group (G1).

\section{CONCLUSION}

The relationships between chromosome abnormalities and reproductive problems were concluded in the study. The cytogenetic study (chromosomal analysis) should be regularly used as a tool to determine the causes of low reproductive efficiency or failures and expectation of fertilizing performance in dairy buffalo. Also, animals showing high percentage of chromosomal aberrations should be culled from breeding program in early ages, particularly incidence of centromeric attenuation. This study was the first proved that centromeric attenuation is highly associated with reproductive failures. More studies and investigations are still required in this regard.

\section{REFERENCES}

Ahmed, W. M., H. A. Sabra, E. M. Hanafi and S. I. S. Shalaby, 2002. The present situation of ovarian inactivity of cows and buffaloes in Egypt. Beni Suef. Vet. Med. J., (12): 13-46.

Ahmed, W. M., H. H. El-Khadrawy, E.M Hanafy, A.H. Ali and S.A. Shalaby, 2010. Clinical perspective of repeat breeding syndrome in buffaloes. J. Am. Sci., 6(11): 661-666.

Di Meo G.P., A. Perucatti, R. Di Palo, A. Iannuzzi, F. Ciotola, V. Peretti, G. Neglia,G. Campanile, L. Zicarelli and L. Iannuzzi, 2008. Sex chromosome abnormalities and sterility in river buffalo. Cytogenet. Genome Res., (120): 127-131.

Di Meo G.P., A. Perucatti, V. Genualdo, A. Iannuzzi, F. Sarubbi, A. Caputi-Jambrenghi, D. Incarnato, V. Peretti, G. Vonghia and L. Iannuzzi, 2011. Arare case of centric fission and fusion in a river buffalo (Bubalus bubalis, 2n=50) cow with reduced fertility. Cyto.Geno.Res., 132 (1-2): 2630.

Dochi, O., K. Takahashi, T. Hirai, and H. Koyama, 2008. The use of embryo transfer to produce pregnancies in repeat-breeding dairy cattle. Theriogenology, (69): 124-128.

El-Bayomi K. h., M. Iman, E. El-Araby and A. W. Zaglool, 2011. Cytogenetic analysis related to some infertility problems in cattle. Global V., 7 (4): 323-329.

El-Khadrawy H. H., W.M. Ahmed and E. M. Hanafi, 2011. Observations on repeat breeding in farm animals with emphosis on its control. J. Reprod. Infert. 2 (1): 1-7.

Genualdo V., A. Perucatti, A. Iannuzzi, G. P. Di Meo, S. M. Spagnuolo, A. Caputi-Jambrenghi, A. Coletta, G. Vonghia and L. Iannuzzi, 2012. Chromosome fragility in river buffalo cows exposed to dioxins. J. Appl. Genet. 53(2): 221226.

Halnan, C.R.E. 1977. An improved technique for the preparation of chromosomes from cattle whole blood. Res. Vet. Sci., 22: 40-43.

Iannuzzi L. and D. Berardino, 2008. Tools of the trade: diagnostics and research in domestic animal cytogenetics. J. Appl. Gene., 4: 357-366.

Ioana-Nicolae, 2007. The role of cytogenetics in the genetic improvement of cattle. $3^{\text {rd }}$ Joint Meeting of the Network of Universities and Research Institutions of Animal Science of the South Estern European Countries, Thessaloniki 10-12 February.

Maria, I.N. and W.A. King, 2004. Genetic factors that affect normal reproduction and fertility in domestic cattle. Vet. Bull., 74 (11): 140-147.

Murali, N., P. Devendran and S. Panneerselvam, 2009. Cytogenetic studies on the chromosomes of TODA Buffaloes. Buff. Bull., 28 (2): 95-100.

Nutrient Requirement of Dairy Cattle. NRC, 2013. Recommendation for dairy cows. Animal Manure Management. July 16, 2013.

Patel R.K., K.M. Singh, K.J. Soni and J.B. Chauhan, 2006. Novel cytogenetic finding: an unusual X;Xtranslocation in Mehsana buffalo (Bubalus bubalis). Cyt. Geno. Res., 115(2): 186-188.

Patel D.J., A.J. Patel, R.K. Patel and P.R. Parekh, 2012. Chromosomal analysis of breeding bulls using lymphocyte culture. The Bangladish Vet. 29 (1): 17-21.

Parakinson, T., 2009. The repeat breeder syndrome. In: D.E. Noakes, T.J. Parkinson and G.C.W. England, Eds. Veterinary Reproduction and Obstetrics ( $9^{\text {th }}$ ed). Elsevier, pp: 463-466.

Saleh, A.A., 2008. Cytogenetic studies related to some reproductive disorders in cattle. M.Sc. Thesis, Fac. Vet. Med., Zaga. Univ.

Sheldon, I.M., G. Lewis, S. LeBlanc and R. Gilbert, 2006. Defining postpartum uterine disease in dairy cattle. Theriogenol., 65: 1516-1530.

SPSS, 2006. Statistical Package for Social Science, SPSS for windows Release 14.0.0, All Rights Reserved, Copyright ${ }^{\circledR}$ SPSS Inc. 
دراسة سيتولوجية على الاخفاقات التناسلية فى اناث الجاموس المصرى

محمد فهمى سعد'، أيمن مصطقى سعيد"، سامى أنور درويش"، سويفى عبد الرحيم سويفى؛

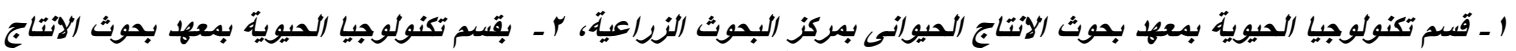

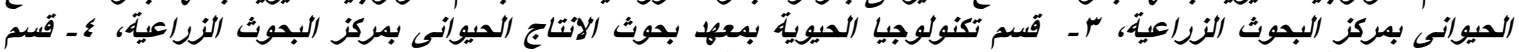

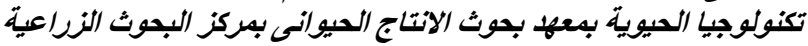

يعتبر التحليل الكروموسومى هو أحد الطرق الهامة فى تحديد وتتخيص المشاكل التناسلية للحيوانات المزرعية. فهناك ارتباط بين

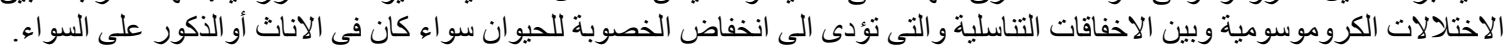

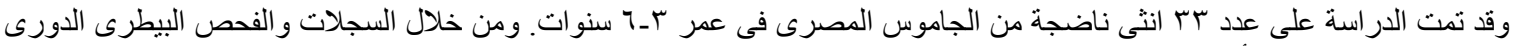
فقد قسمت الحيو انات كالأتى:

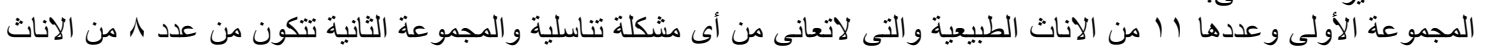

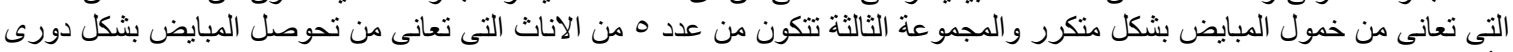

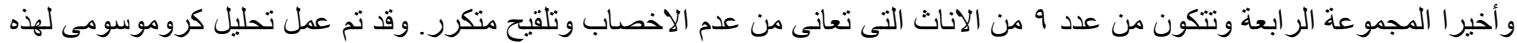

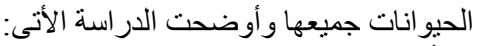

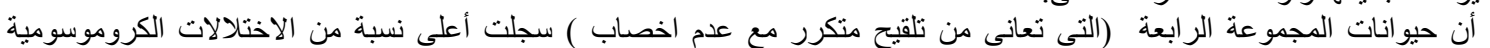

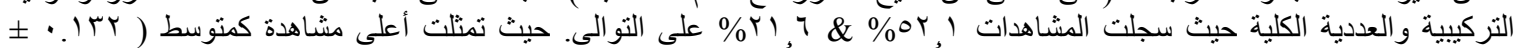

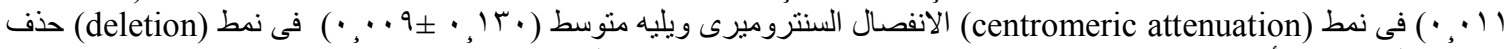

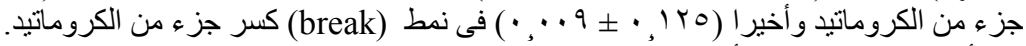

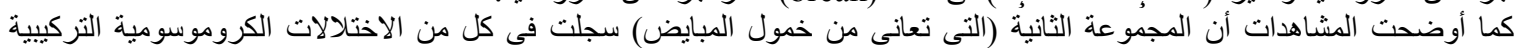

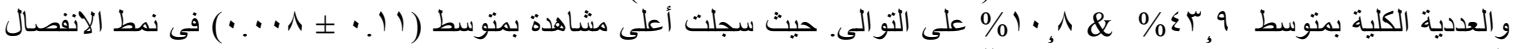

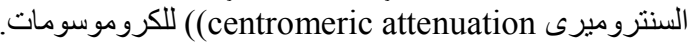

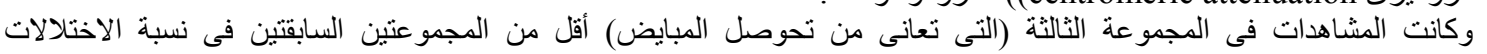

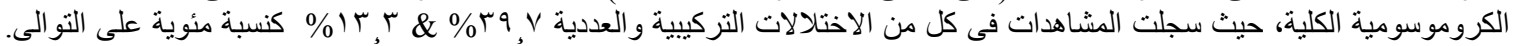

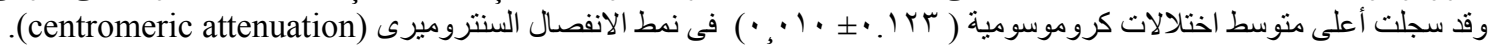

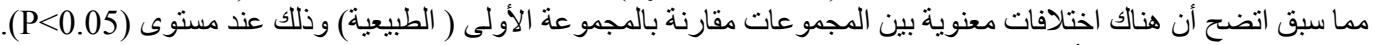

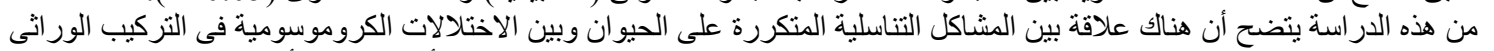

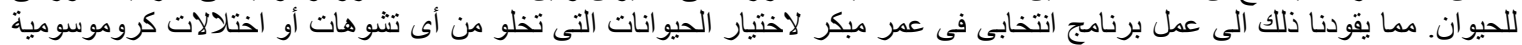

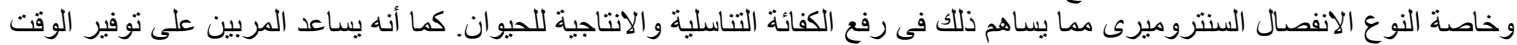
و الجهذ و المال في مز الارع الإل الانتاج الحيو انى. 